\title{
Cationic Polymerization Induced by Tris-(p-bromophenyl) Amine Cation-Radical Salts
}

\author{
Ideisan I. Abu-Abdoun*
}

Department of Chemistry, University of Sharjah, Sharjah P.O. Box: 27272, UAE

\begin{abstract}
Substituted triphenylamine cation radical salts having anions of the type $\mathrm{SbF}_{6}^{-}, \mathrm{PF}_{6}^{-}, \mathrm{BF}_{4}^{-}$and $\mathrm{SbCl}_{6}^{-}$, were prepared and used to initiate cationic polymerization of cyclohexene oxide (CHO), tetrahydrofuran (THF), and $\mathrm{N}$-vinyl carbazole (NVC), thermally in dichloromethane at room temperature. Experimental results are presented to show the effects of salt counter ion, concentration, and polymerization conditions on the yield and the molecular weight of the obtained polymer. THF polymerization was enhanced by photolysis of the reaction mixture for short time. A general mechanism for the polymerization by cation-radical salts of substituted triphenylamine is proposed.
\end{abstract}

Keywords: Tris-(p-bromophenyl) amine. Cation radical salts. Cationic polymerization. N-vinyl carbazole. Cyclohexene oxide. Tetrahydrofuran.

\section{INTRODUCTION}

Great effort has been devoted in developing systems that may initiate the polymerization processes through various known mechanisms. Cationic polymerization is widely applicable for both vinyl and ring opening polymerizations giving place to many studies of both academic and industrial interests [1]. Thermally stable onium salts, such as diaryliodonium [2], triarylsulfonium [3], phosphonium and arsonium salts $[4,5]$ in the presence of low nucleophilic complex metal halide anions are well established photo initiators for cationic polymerization.

It has been suggested that photolysis of triarylsulfonium and diaryliodonium salts results in the cleavage of a carbon - sulfur or a carbon - iodine bond to yield reactive radical cation as shown in the equations (1\&2) below:

$$
\begin{aligned}
& \mathrm{Ar}_{3} \mathrm{~S}^{+} \mathrm{X}^{-}-\mathrm{h} \mathrm{W}-\mathrm{Ar}_{2} \mathrm{~S}^{+} \mathrm{X}^{-}+\mathrm{Ar}^{-} \\
& \mathrm{Ar}_{2} \mathrm{I}^{+} \mathrm{X}^{-}-\mathrm{Ar} \mathrm{Xr}^{+}+\mathrm{Ar}
\end{aligned}
$$

Accordingly, the interaction of the produced cation radical with the monomer is expected to produce the initiating species.

Recently, we reported on the cationic polymerization of epoxide and vinyl monomers initiated by cation radical salts of phenothiazine derivatives (salt 1) [5], and N, N, N,N-tetraphenyl-p- phenelenediamine (salt 2) [6].

*Address correspondence to this author at the Department of Chemistry, University of Sharjah, Sharjah P.O. Box: 27272, UAE; Tel: 06-505 3810; Fax: 06-505 3820; E-mail: abuabdoun@sharjah.ac.ae

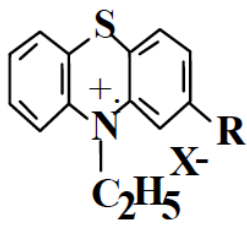

Salt 1

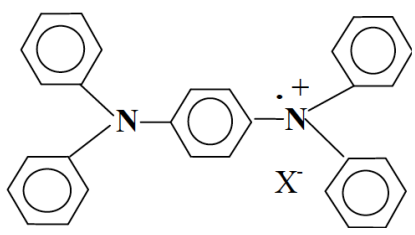

Salt 2
Triphenylamine derivatives are well known hole transport materials with very high charge transport mobility, which are frequently used in light emitting devices and organic displays $[7,8]$. Tris-p-substituted triphenylamine are readily oxidized to form stable cation- radicals, which have been shown to have a useful role as one electron oxidizing agents for the organic molecules, especially as the intense visible and ESR spectra of these salts provide convenient probes for monitoring reactions $[9,10]$.

This paper describes the synthesis of tris-(pbromophenyl) amine cation radical salt (structure 3 ), and its use in cationic polymerization of selected epoxide and vinyl monomers at room temperature.

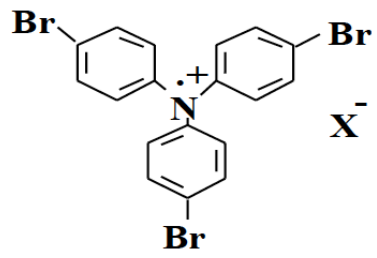

Salt $3 \quad X=\mathrm{SbF}_{6}, \mathrm{PF}_{6}, \mathrm{BF}_{4}, \mathrm{SbCl}_{6}$

\section{EXPERIMENTAL}

\subsection{Materials}

Tris-(p-bromophenyl) amine was obtained by a known procedure $[11,12]$. Monomer cyclohexene oxide, 
tetrahydrofuran, and $\mathrm{N}$-vinylcarbazole, solvents used in this work were obtained from Aldrich Chemical Co. and were dried over calcium hydride and distilled before use. Melting points were recorded on a Thomas Hoover Capillary melting apparatus.

\subsection{Spectroscopic Measurements}

Ultraviolet spectra were obtained on a Unicam SP1800 Ultraviolet Spectrophotometer. Infrared spectra were recorded using potassium bromide $(\mathrm{KBr})$ disc with a Perkin-Elmer grating infrared spectrophotometer (Model 577). NMR spectra were taken in $\mathrm{CDCl}_{3}$, on a Perkin-Elmer $60 \mathrm{MHZ}$ spectrometer (Model R12B) using deuterated solvents with tetramethylsilane as the internal standard.

\subsection{Polymerization Reactions}

\section{Cyclohexene Oxide and $\mathrm{N}$-Vinylcarbazole}

Selected amounts of the monomer and the initiator (salt 3), in dichloromethane were placed into a Pyrex tube closed with rubber septum and flushed with nitrogen. The tube was placed on a holder and left immersed for the required period in a water bath at 25 ${ }^{\circ} \mathrm{C}$. Rapid addition of initiator was achieved by syringe injection.

\section{Tetrahydrofuran}

Selected amounts of THF and initiator were placed in a $12 \mathrm{~mm}$ diameter Pyrex tube. The solution degassed under vacuum by conventional freeze thaw techniques and sealed off under vacuum. The reaction mixture was heated at $50{ }^{\circ} \mathrm{C}$ for the times indicated in the case of thermal polymerization; where as, in case of photopolymerization the reaction mixtures were irradiated from Rayonet Merry-go-round photoreactor with $350 \mathrm{~nm}$ for 5 minutes; during this time colorless reaction mixture was obtained.

After polymerization, the polymer was precipitated into methanol, filtered, dried, and weighed. Polymer yield percentage and rate of polymerization were determined gravimetrically $[5,6]$. The number averaged molecular weight $(\mathrm{Mn})$ of the isolated polymer was measured in toluene on a Hewlett Packard (Model 501), and High-Speed Membrane Osmometer in toluene. Molecular weight distributions were determined using a Waters Associates (Model 200) GPC, fitted with differential refractometer detector. The systems were examined at $25^{\circ} \mathrm{C}$ in THF with a solvent flow rate of $1.0 \mathrm{~mL} / \mathrm{min}$ and a polymer concentration of $1.0 \mathrm{mg} / \mathrm{mL}$. Molecular weights were calculated with reference to polystyrene standards.

\section{RESULTS AND DISCUSSIONS}

\subsection{Synthesis of the Cation Radical Salts}

The following chemical oxidation methods were used in the preparation of salts (3).

\section{A. Oxidation with $\mathrm{SbCl}_{5}\left(X=\mathrm{SbCl}_{6}^{-}\right)$.}

5.0 grams of neutral amine were dissolved in $50 \mathrm{ml}$ dichloromethane in a three-necked flask fitted with magnetic stirrer, dropping funnel, nitrogen bleed, and calcium chloride exit tube. The mixture was stirred for a few minutes then a solution of $5 \mathrm{~mL}$ of $70 \%$ antimony pentachloride in dichloromethane $(25 \mathrm{~mL})$ then it was added slowly to the reaction mixture. The reaction was instantaneous, and the deep blue colored solution quickly darkened. The mixture was stirred for a further 20 minutes, then poured into $500 \mathrm{~mL}$ of cold dry low boiling ether $\left(40-60{ }^{\circ} \mathrm{C}\right)$. The product was collected by suction filtration and washed thoroughly with dry ether in order to remove any traces of unreacted antimony chloride. By pumping the salt under high vacuum, the final traces of solvent were removed. The salt consisted of fine blue needle-shaped crystals and was stored under vacuum in the dark. The yield was approximately $80 \%$.

\section{B. Oxidation with Silver Salt and lodine}

Dry powdered silver hexafluoro antimonate (3.60 grams) was dissolved in $30 \mathrm{ml}$ of dry dichloromethane by stirring magnetically for at least 15 minutes in a three-necked flask fitted as described in Part A above. 0.3 gram of the neutral amine was added, and the
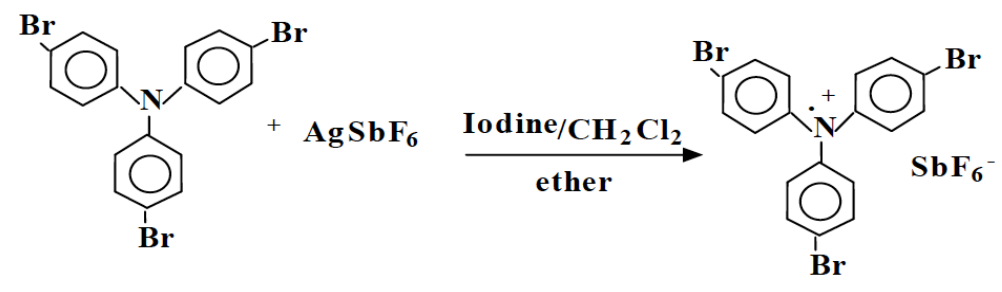

Scheme 1: 
Table 1: Characterization of the Cation Radical Salts 3

\begin{tabular}{|c|c|c|c|c|c|c|c|}
\hline \multirow{2}{*}{$x^{-}$} & \multirow{2}{*}{ m.pt. $\left({ }^{\circ} \mathrm{C}\right)$} & \multirow{2}{*}{$\Lambda_{\max }(\mathrm{nm})$} & \multirow{2}{*}{$\varepsilon_{\max }\left(\mathrm{CH}_{2} \mathrm{Cl}_{2}\right)\left(\mathrm{Im}^{-1} \mathrm{~cm}^{-1}\right)$} & \multicolumn{4}{|c|}{ Elemental Analysis } \\
\hline & & & & & $\% \mathrm{C}$ & $\% \mathrm{H}$ & $\% \mathrm{~N}$ \\
\hline \multirow{2}{*}{$\mathrm{BF}_{4}^{-}$} & \multirow{2}{*}{$244-246$} & \multirow{2}{*}{725} & \multirow{2}{*}{$4.76 \times 10^{4}$} & calc. & 38.24 & 2.14 & 2.47 \\
\hline & & & & Found & 39.28 & 2.32 & 2.63 \\
\hline \multirow{2}{*}{$\mathrm{PF}_{6}^{-}$} & \multirow{2}{*}{$139-241$} & \multirow{2}{*}{725} & \multirow{2}{*}{$6.40 \times 10^{4}$} & calc. & 34.63 & 1.93 & 2.24 \\
\hline & & & & Found & 35.33 & 2.0 & 2.24 \\
\hline \multirow{2}{*}{$\mathrm{SbF}_{6}^{-}$} & \multirow{2}{*}{$190-292$} & \multirow{2}{*}{725} & \multirow{2}{*}{$7.60 \times 10^{4}$} & calc. & 30.24 & 1.69 & 1.95 \\
\hline & & & & Found & 30.45 & 1.74 & 1.94 \\
\hline \multirow{2}{*}{$\mathrm{SbCl}_{6}^{-}$} & \multirow{2}{*}{$142-244$} & \multirow{2}{*}{725} & \multirow{2}{*}{$6.70 \times 10^{4}$} & calc. & 26.47 & 1.48 & 1.71 \\
\hline & & & & Found & 25.44 & 1.56 & 1.69 \\
\hline
\end{tabular}

mixture was stirred for further 10 minutes and then cooled in a dry ice-acetone bath (Scheme 1).

1.80-gram resublimed iodine in $30 \mathrm{~mL}$ of cold and dry diethyl ether, was added over 5 minutes during which time blue crystals began to appear. The reaction mixture was then worked up as described in the oxidation with $\mathrm{SbCl}_{6}$.

Solution of the isolated salt 3 was found to be stable in dichloromethane, for a period of several days under laboratory conditions. Table 1 shows the physical and spectroscopic characterization of salt 3 .

\subsection{Polymerization Reactions}

\subsubsection{Polymerization of Cyclohexene Oxide}

Polymer was formed from cyclohexene oxide, which does not polymerize by free radical mechanism, in the presence of salt (3) as shown in equation (3).

Salt $4+$<smiles>C1CCC2OC2C1</smiles>

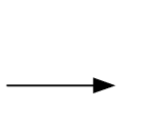<smiles>[Y]C1CCCCC1O</smiles>

The reaction mixture contained $0.988 \mathrm{M}$ monomer and $2.15 \times 10^{-4} \mathrm{M}$ salt (3) in dichloromethane, at $25{ }^{\circ} \mathrm{C}$. The color of the reaction mixture changed from blue to orange/red upon addition of the initiator solution. Polymerization by salt $3\left(\mathrm{X}=\mathrm{SbCl}_{6}\right)$ was carried out and the results are shown in Figure 1 . The rate of polymerization of cyclohexene oxide monomer increased with polymerization time within the reported experimental conditions.

\subsubsection{Polymerization of $\mathbf{N}$-Vinylcarbazole}

$\mathrm{N}$-Vinyl carbazole is an easily purified crystalline monomer, and can be polymerized by cationic, anionic and free radical mechanisms. The mechanism of NVC initiation by ammoniumyl salt which was suggested by Ledwith, which involve electron transfer and the production of the monomer cation radical could be applicable here [13]. Salt 3 having $\mathrm{SbCl}_{6}$ anion, and they used relatively high concentration $\left(10^{-3} \mathrm{M}\right)$.

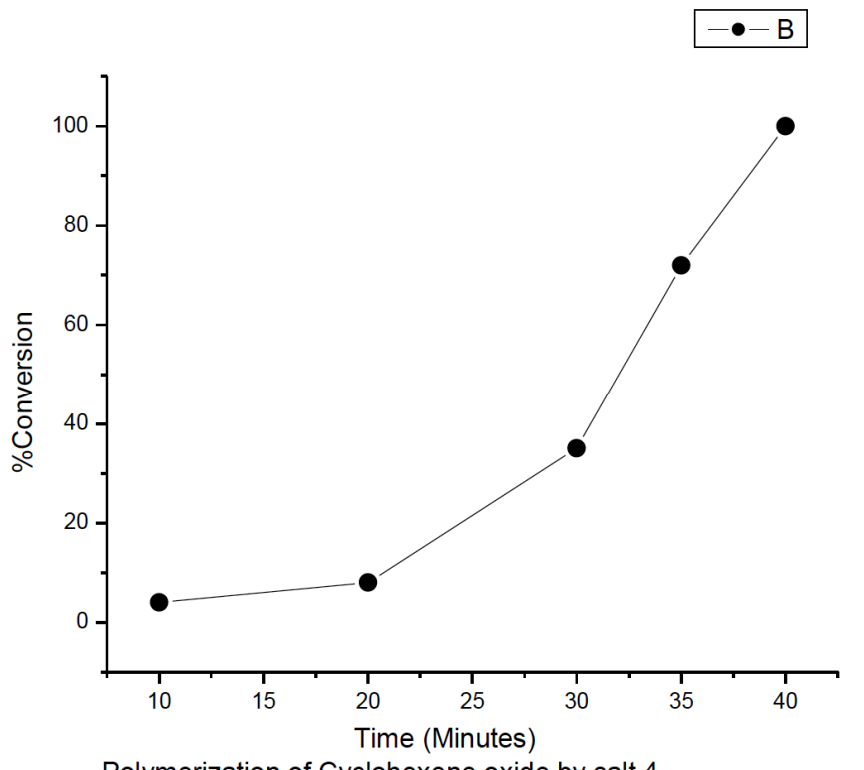

Polymerization of Cyclohexene oxide by salt 4

Figure 1: Polymerization of cyclohexene oxide by salt (3) (X $=\mathrm{SbCl}_{6}{ }^{-}$).

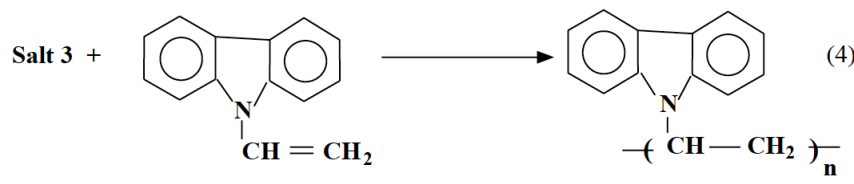

Ammoniumyl cation radical salt $3, \mathrm{X}=\mathrm{PF} 6, \mathrm{SbF}_{6}$, $\mathrm{SbCl}_{6} . \mathrm{BF}_{4)}$ has been used to initiate $\mathrm{N}$-vinyl carbazole polymerization in this work, in order to investigate the counter ion effect. The concentration of cation radical salt was $2.85 \times 10^{-5} \mathrm{M}$, whereas $\mathrm{N}$-vinylcarbazole 
Table 2: Effect of Salt 3 Counter Ion on the Polymerization of N-Vinylcarbazole

\begin{tabular}{|c|c|c|c|c|}
\hline $\mathbf{X}$ & $\mathbf{P F}_{6}^{-}$ & $\mathbf{S b F}_{6}^{-}$ & $\mathbf{S b C l}_{6}^{-}$ & $\mathbf{B F}_{4}^{-}$ \\
\hline \hline \% Conversion & 42.1 & 35.2 & 24.8 & 6.2 \\
\hline
\end{tabular}

concentration was $0.0785 \mathrm{M}$ in dichloromethane at $25^{\circ} \mathrm{C}$. During the reaction mixing time was very short and just to allow mixing, colorless reaction mixture was obtained.

The rates of polymerization of NVC fall in the following sequence according to the nature of the counter ion $\mathrm{PF}_{6}>\mathrm{SbF}_{6}>\mathrm{SbCl}_{6}>\mathrm{BF}_{4}$, as shown in Table 2. This indicates that termination due to counter ion fragmentation was a feasible process and could be the same as reported here for cyclohexene oxide polymerization, due to the type of the monomer and the relative instability of the counter ion.

The effect of the counter ion effect shown in Table 2 could be due to the termination of the growing polymer chain by the counter ion, and salts having the $\mathrm{PF}_{6}{ }^{-}$ counterion is more reactive due to the greater stability of the counterion $\mathrm{PF}_{6}{ }^{-}$as shown in equations (5-8).

$\mathrm{H}^{+} \mathrm{PF}_{6}^{-}{ }^{-}------>>$stable anion $\left(\mathrm{PF}_{6}^{-}\right)+\mathrm{H}^{+}$

$\mathrm{BF}_{4}^{-}------------>F^{-}+\mathrm{BF}_{3}$

$\mathrm{BF}_{3}+$ monomer --------------> polymer chain

$\mathrm{F}^{-}+$propagated chain -----------> dead polymer

Based on the stability of the counter ion and it is ability to fragment and give $\mathrm{F}^{-}$ion the rate of polymerization in Table 2 varies from high to low, in the following sequence order:

$\mathrm{PF}_{6}{ }^{-}>\mathrm{SbF}_{6}{ }^{-}>\mathrm{SbCl}_{6}{ }^{-}>\mathrm{BF}_{4}{ }^{-}$.

In case of NVC polymerization above, where instantaneous initiation and lack of termination is assumed, this enable the kinetics to be simplified and the propagation rate constant $\left(k_{p}\right)$ to be determined, using equation (11):

$R_{p}=k_{p}\left[M_{o}\right]\left[C_{o}\right]$

Where; $R_{p}$ is the rate of polymerization, $\left[M_{o}\right]$ and $\left[\mathrm{C}_{0}\right]$ are the initial monomer and initiator concentrations, respectively. The calculated $\left(k_{p}\right)$ for polymerization of $\mathrm{N}$-vinyl carbazole is found to be 1.29 $\mathrm{x} 10^{-1} \mathrm{~L} . \mathrm{m}^{-1} \mathrm{~s}^{-1}$, which reasonably in agreement with expectation, considering the relative reactivity of NVC.

\subsubsection{Polymerization of Tetrahydrofuran (THF)}

The polymerization of THF initiated by salt 3 showed typical behavior of a living system, and it was interesting to notice that the rate of polymerization was slow at the beginning then increased with time.

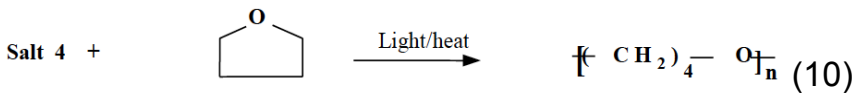

A comparison between thermal and photopolymerization of THF monomer by salt 3 is shown in Figure 2. Photolysis of the salt-monomer mixture had a remarkable effect on accelerating the polymerization rate and the effect of bleaching the color of the salt. Variation in the produced polymer molecular weight with time is shown in Figure $\mathbf{3}$ for both thermal and photo polymerization.

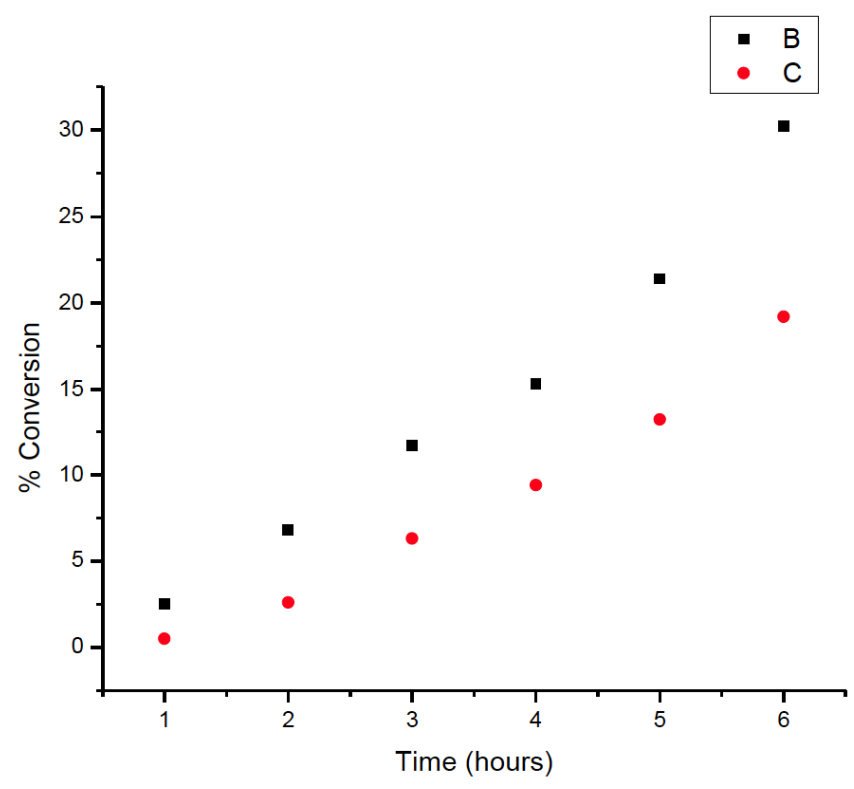

Figure 2: Polymerization of THF, effect of photolysis time by salt (3) $\mathrm{X}^{-}=\mathrm{SbF}_{6}$.

Analysis of the accelerating portion of curves such as the showed in Figure 3 gives a measure of the instantaneous rate of polymerization at a given time of reaction.

Using the rate expression given in equation (11) [13-15], it is then a simple matter to estimate the number of active centers present at any time. It has been found that from Figure 3 , about $51 \%$ of the initiator present produced active centers in photo- 
induced polymerization, while for the thermal polymerization process there was $38 \%$ conversion of the initiator to active centers.

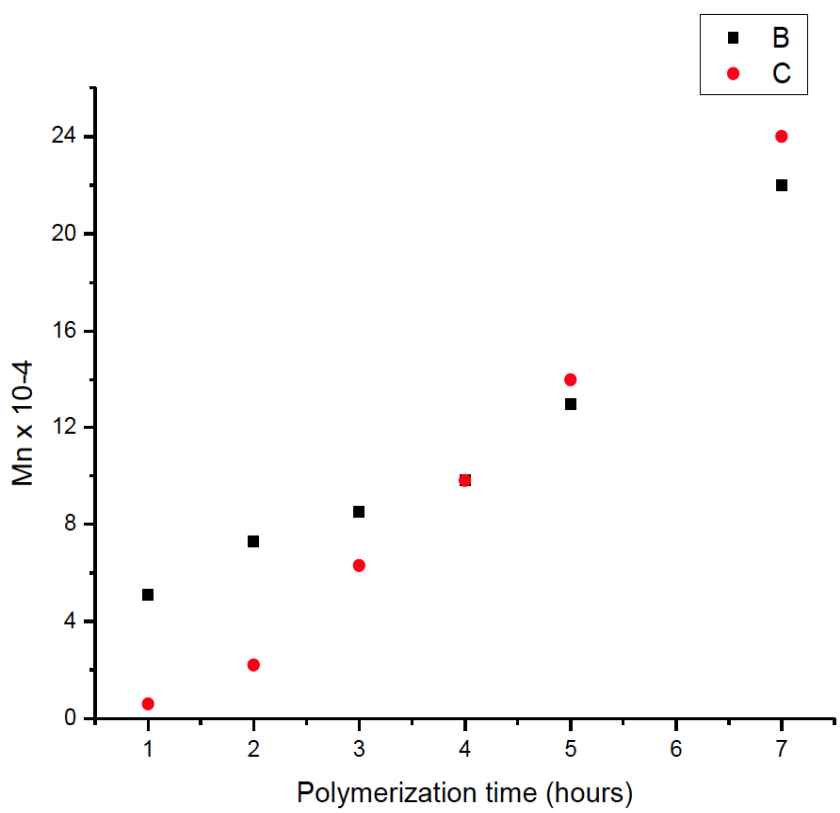

Figure 3: Polymerization of THF, number average molecular weight $(\mathrm{Mn})$ change with polymerization time.

\section{$\mathrm{Rp}=\mathrm{Kp}[\mathrm{THF}][$ active centers $]$}

Poly THF prepared by salt (3), showed neutral amine end groups, from the GPC analysis with UV detecting $(\lambda=307 \mathrm{~nm})$ in THF eluting solvent, after several precipitations of the polymer. This suggests that the initial reaction between cation radical and THF must involve the formation of an oxonium ion, which propagates by a series of nucleophilic displacement by THF molecules at $\alpha$ - carbon atom. Therefore, it is possible that the same series of initiation reactions proposed for cyclohexene oxide polymerization may be involved. It is also recognized that electron transfer from the monomer (THF) to form $[\mathrm{THF}]^{+}$which undergoes further decomposition may also be involved:

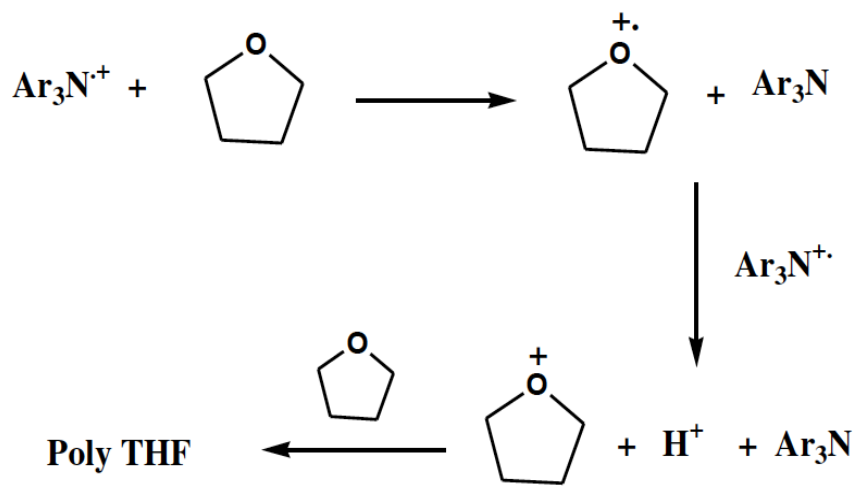

Scheme 2:

\subsection{Polymerization Mechanism and Counter Ion Effect}

The counter ion may undergo a reaction with the growing chain to terminate the polymer chain by proton loss (chain transfer, since the catalyst is regenerated) or by addition of the gegenion to the polymer (chain termination, since the catalyst is destroyed). The hexafluoroantimonate anion is apparently much better at stabilizing the oxonium ion than anions such as $\mathrm{BF}_{4}$ or $\mathrm{SbCl}_{6}^{-}$.

The low nucleophilicity of $\mathrm{SbF}_{6}^{-}$anion, minimizes or prevents reaction of the growing chains of the counter ion. Transfer to monomer is most likely caused in this cationic polymerization. For cyclohexene oxide polymerization, the chain transfer process could be represented as in Scheme $2[16,17]$.
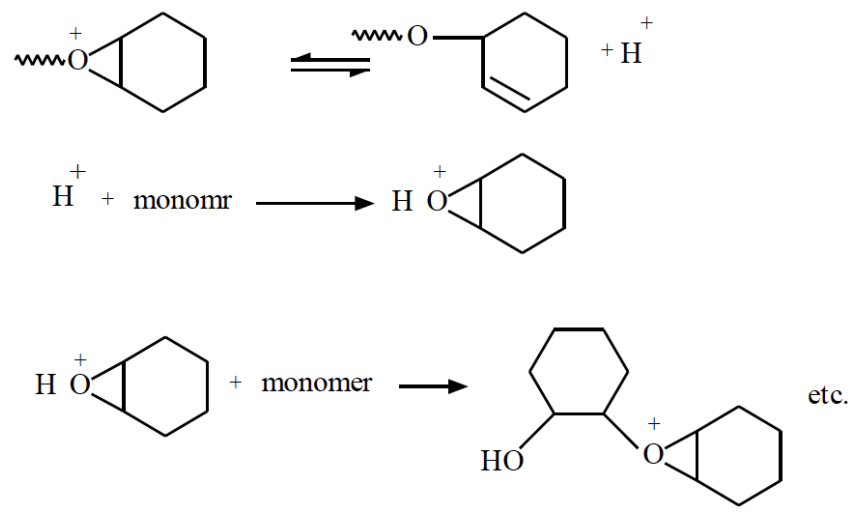

Scheme 3: Chain Transfer to Monomer.

The mechanism for initiation of the polymerization of cyclohexene oxide by ammoniuymyl salt (3), and consistent with the reports on the reactions of cation radicals with weak nucleophiles [18], is shown in Scheme 4 below.

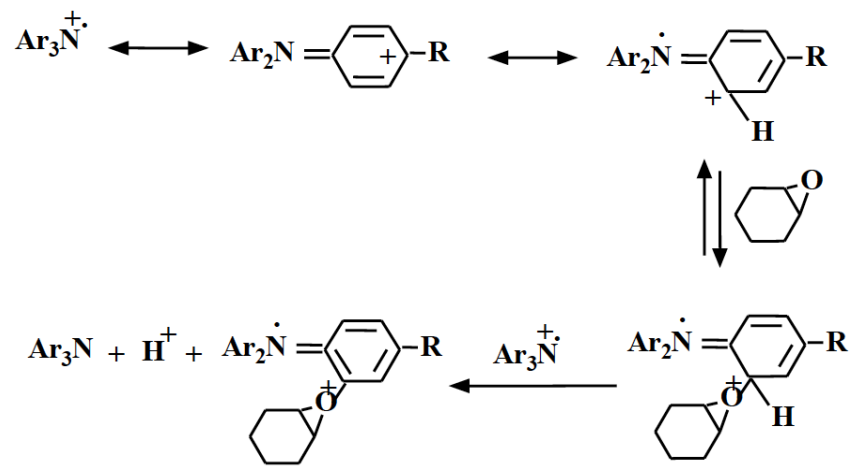

Scheme 4: The Mechanism of Polymerization of Cyclohexene Oxide by Salt 3 .

Polymer chains would grow (and undergo transfer to monomer) as indicated, following thermal initiation 
by both the protonic acid produced and the amine ended cyclic oxonium ion.

\section{CONCLUSION}

Chemically prepared cation radical salts of parasubstituted triphenylamine were found to be effective thermal initiators for the cationic polymerization of epoxide and vinyl monomers. The polymerization rate was affected by the nature of the counterion and the monomer structure. Polymerization initiated by salt having the anion $\mathrm{SbF}_{6}^{-}$showed faster rate of initiation in epoxide and cyclic ether polymerization, while in vinyl polymerization salts with PF6- showed more reactivity; this variation in counter ion effects is explained on the stability of the counter ion.

\section{REFERENCES}

[1] Dadashi-Silab S, Doran S, Yagci Y. Photoinduced Electron Transfer Reactions for Macromolecular Syntheses. Chem Rev 2016; 116(17): 10212-10275. https://doi.org/10.1021/acs.chemrev.5b00586

[2] Sangermano M. Advances in cationic photopolymerization. Pure Appl Chem 2012; 84(10): 2089-2101. https://doi.org/10.1351/PAC-CON-12-04-11

[3] Crivello JV. The discovery and development of onium salt cationic photoinitiators. J Polym Sci Polym Chem 1999; 37: 4241.

https://doi.org/10.1002/(SICl)10990518(19991201)37:23<4241::AID-POLA1>3.0.CO;2-R

[4] Schlegel L, Schabel W, Dufour P. In Radiation Curing in Polymer Science and Technology. Fouassier JP, Rabek JF, Eds. Elsevier, London 1993; Vol. I: p. 119.

[5] Abu-Abdoun I, Aal-e-Ali. Photopolymerization of cyclohexene oxide by Phosphonium and Arsonium salts. European Polymer Journal 1993; 29(11): 1445-1450. https://doi.org/10.1016/0014-3057(93)90056-L

[6] Abu-Abdoun I, Ledwith A. Cationic polymerization photochemically and thermally induced by phenothiazine cation radical salts. Europ Polym J 1997; 33: 1671-1677. https://doi.org/10.1016/S0014-3057(97)00044-X
$[7]$

Abu-Abdoun I, Ledwith A. Photochemically and Thermally Induced polymerization by N, N, N, N Tetraphenylene amine Cation radical Salts. J Macromol Sci - Pure and Appl Chem 1998; A35(4): 673-690.

https://doi.org/10.1080/10601329808002005

[8]

Tokito H, Tanaka A, Okada Y, Taga. High-temperature operation of an electroluminescent device fabricated using a novel triphenylamine derivative. Appl Phys Lett 1996; 69(7): 878.

https://doi.org/10.1063/1.117974

[9] Kimura M, Inoue S, Shimada K, Tokito S, Noda K, Taga Y, Sawaki Y. Spirocycle-incorporated triphenylamine derivatives as an advanced organic electroluminescent material. Chem Lett 2000; 2: 192-193. https://doi.org/10.1246/cl.2000.192

[10] Fehervari AF, Kagumba LC, Hadjikyriacou S, Chen F, Gaudiana RA. Ultraviolet-emitting conjugated polymer poly $\left(9,9^{\prime}\right.$-alkyl-3,6-silafluorene) with a wide band gap of 4.0 eV. J Appl Polym Sci 2003; 87: 1634. https://doi.org/10.1002/app.11606

[11] Bawn $\mathrm{CH}$, Bell FA, Ledwith A. Oxidation by a cation radical: electron transfer from 1,1-bis-(p-dimethylaminophenyl) ethylene. Chem Comm 1968; 599.

https://doi.org/10.1039/c19680000599

[12] Walter RI. J Amer Chem Soc 1966; 88: 1923 https://doi.org/10.1021/ja00961a014

[13] Ledwith A, Sherrington DC., Macromolecular Synthesis 1972; 4: 183.

[14] Croucher TG, Walter RE. Polymer 1976; 17: 205. https://doi.org/10.1016/0032-3861(76)90101-4

[15] Dreyfuss MP. p-Chlorophenyldiazonium hexafluorophosphate as a catalyst in the polymerization of tetrahydrofuran and other cyclic ethers. J Poly Sci Part-A Poly Chem Ed 1966; 4: 92179-2200. https://doi.org/10.1002/pol.1966.150040913

[16] Yagci Y, Ledwith A. Mechanistic and Kinetic-Studies on the Photoinitiated Polymerization of Tetrahydrofuran. J Poly Sci Part-A Poly Chem Ed 1988; 26(7): 1911-1918. https://doi.org/10.1002/pola.1988.080260717

[17] Abu-Abdoun I, Aal-e-Ali. Cationic Photopolymerization of cyclohexene oxide. European Polymer Journal 1992; 28(1): 73-78.

https://doi.org/10.1016/0014-3057(92)90239-X

[18] Svanholm U, Parker VD. Kinetics and mechanisms of the reactions of organic cation radicals and dications. IV. Firstand second-order reactions of thianthrene cation radical with phenol. J Amer Chem Soc 1976; 98: 997-1002. https://doi.org/10.1021/ja00420a023

\section{DOl: https://doi.org/10.6000/1929-5995.2019.08.04}

(C) 2019 Ideisan I. Abu-Abdoun; Licensee Lifescience Global.

This is an open access article licensed under the terms of the Creative Commons Attribution Non-Commercial License (http://creativecommons.org/licenses/by-nc/3.0/) which permits unrestricted, non-commercial use, distribution and reproduction in any medium, provided the work is properly cited. 